\title{
A Transcriptomic Insight into the Impact of Colon Cancer Cells on Mast Cells
}

\author{
Yingxin Yu ${ }^{1}$, Bart R. Blokhuis ${ }^{1}$, Johan Garssen ${ }^{1,2} \mathbb{D}$ and Frank A. Redegeld ${ }^{1, * \mathbb{D}}$ \\ 1 Division of Pharmacology, Utrecht Institute for Pharmaceutical Sciences, Faculty of Science, \\ Utrecht University, 3584CG Utrecht, The Netherlands; y.yu@uu.nl (Y.Y.); b.r.j.blokhuis@uu.nl (B.R.B.); \\ j.garssen@uu.nl (J.G.) \\ 2 Nutricia Research, 3584CT Utrecht, The Netherlands \\ * Correspondence: F.A.M.Redegeld@uu.nl
}

Received: 8 March 2019; Accepted: 1 April 2019; Published: 4 April 2019

\begin{abstract}
Mast cells (MCs) are one of the first immune cells recruited to a tumor. It is well recognized that MCs accumulate in colon cancer lesion and their density is associated with the clinical outcomes. However, the molecular mechanism of how colon cancer cells may modify MC function is still unclear. In this study, primary human MCs were generated from $\mathrm{CD} 34^{+}$progenitor cells and a 3D coculture model was developed to study the interplay between colon cancer cells and MCs. By comparing the transcriptomic profile of colon cancer-cocultured MCs versus control MCs, we identified a number of deregulated genes, such as MMP-2, VEGF-A, PDGF-A, COX2, NOTCH1 and ISG15, which contribute to the enrichment of cancer-related pathways. Intriguingly, pre-stimulation with a TLR2 agonist prior to colon cancer coculture induced upregulation of multiple interferon-inducible genes as well as MHC molecules in MCs. Our study provides an alternative approach to study the influence of colon cancer on MCs. The transcriptome signature of colon cancer-cocultured MCs may potentially reflect the mechanism of how colon cancer cells educate MCs to become pro-tumorigenic in the initial phase and how a subsequent inflammatory signal-e.g., TLR2 ligands-may modify their responses in the cancer milieu.
\end{abstract}

Keywords: mast cells; colon cancer; 3D coculture; transcriptome

\section{Introduction}

Mast cells (MCs) are among the first immune cells recruited in the initial phase of tumorigenesis [1]. Once MCs migrate to a tumor site, many immunologic and non-immunologic factors present in the cancer microenvironment can regulate their phenotypes and functions [2,3]. It has been well recognized that MCs accumulate in colon cancer and their number is associated with microvessel formation and the disease prognosis [2,4]. The majority of studies show that MCs promote colon cancer progression [5-10], while only a few had an opposite observation and suggested that higher MC numbers correlate with better clinical outcomes [11,12]. Upon activation, MCs release a variety of mediators and therefore directly influence tumor growth or indirectly regulate the local immune responses $[1,2]$. For instance, angiogenic factors (e.g., VEGF) and growth factors (e.g., IL-8) facilitate angiogenesis and cancer cell proliferation [13-16]; matrix metalloproteinases (e.g., MMP-9) and proteases (tryptase and chymase) degrade extracellular matrix (ECM) components and thereby favor the implantation of tumor cells $[17,18]$. By releasing TGF- $\beta$, amphiregulin and adenosine, MCs can suppress the protective immune responses against cancer [18,19]. On the other hand, MCs can directly kill tumor cells through ROS (reactive oxygen species) and TNF- $\alpha[2,20]$. They can also indirectly inhibit tumor growth through secreting heparin, IL-9 and stimulation of dendritic cell maturation [2,20]. Despite mounting evidence 
showing the impact of MC-derived mediators on tumor growth, the molecular mechanism is still unknown of how colon cancer cells modify MC phenotype and activity.

The current development of next-generation sequencing of RNA (RNA-seq) and Gene Ontology analysis [21] gives us an opportunity to look into the whole transcriptional landscape of cancer-associated MCs and to predict their activity. However, it is difficult to obtain sufficient numbers of MCs from human colon cancer and healthy colon tissues, due to the limited source of fresh human materials and technical challenges to isolate MCs from such tissue. In this study, primary MCs from human peripheral CD34 ${ }^{+}$stem cells were generated [22] and an in vitro 3D coculture model was developed to study the MC - colon cancer interaction. Our previous data have shown that human MCs promote colon cancer growth and this effect is enhanced by their cellular crosstalk [23]. To understand how colon cancer cells may modify MCs to be pro-tumorigenic, we compared the transcriptomic profile of colon cancer-cocultured MCs versus control MCs and sorted interesting genes using Ingenuity Pathway Analysis (IPA).

\section{Results}

\subsection{Deregulated Genes in Colon Cancer-Cocultured MCs}

To assess the influence of colon cancer cells on MC gene expression, we compared the transcriptome profile of MCs cocultured with HT29 spheroids (CCS) versus MCs cultured only in ECM without HT29 (CTR). Log $_{2}$-transformed gene expression fold change $\left(\log _{2} \mathrm{FC}\right)$ in CCS was calculated over control CTR. At the specified significance level of corrected $p$ value $<0.05$ and $\log _{2} \mathrm{FC}>0.2$, deregulation of 281 genes was found in CCS (Figure 1A and Table 1). IPA pathway enrichment analysis showed the enhancement of "pancreatic adenocarcinoma signaling" and "molecular mechanism of cancer" (Figure 1B), which may support the significance of MCs in cancer pathology. Among the top 10 deregulated genes, MMP2 (Matrix Metallopeptidase 2) is well known for its role in colorectal cancer invasion [24] and EPSTI1 (Epithelial stromal interaction 1) and MPO (Myeloperoxidase) are related to tumor development $[25,26]$.

Table 1. The top 10 deregulated genes in CCS versus CTR.

\begin{tabular}{|c|c|c|c|c|}
\hline Gene Symbol & Name & Gene Expression $\ddagger$ & $\log _{2} \mathrm{FC}$ & Adjusted $p$ Value \\
\hline \multicolumn{5}{|l|}{ upregulated } \\
\hline SLC45A4 & Solute carrier family 45 member 4 & 1.07 & 0.57 & $* * * *$ \\
\hline NAB2 & Nuclear polyadenylated RNA-binding protein & 40.76 & 0.55 & $* * * *$ \\
\hline MPO & Myeloperoxidase & 0.49 & 0.49 & $* * * *$ \\
\hline RFLNB & Refilin-B & 18.00 & 0.46 & $* * * *$ \\
\hline SPRY2 & Protein sprouty homolog 2 & 19.00 & 0.43 & $* * * *$ \\
\hline OASL & $2^{\prime}-5^{\prime}$-oligoadenylate synthase-like protein & 0.21 & 0.43 & $* * * *$ \\
\hline EPSTI1 & Epithelial-stromal interaction protein 1 & 0.39 & 0.42 & $* * * *$ \\
\hline MMP2 & Matrix metalloproteinase-2 & 3.23 & 0.39 & $* * * *$ \\
\hline UNC5B & Netrin receptor UNC5B & 0.20 & 0.38 & $* * * *$ \\
\hline PHLDA1 & Pleckstrin homology-like domain family A member 1 & 0.54 & 0.36 & $* * * *$ \\
\hline \multicolumn{5}{|c|}{ 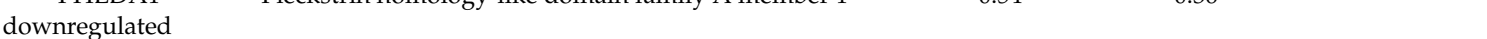 } \\
\hline CDT1 & DNA replication factor & 3.34 & -0.57 & $* * * *$ \\
\hline KIF20A & Kinesin-like protein KIF20A & 3.54 & -0.53 & $* * * *$ \\
\hline ESPL1 & Separin & 1.27 & -0.53 & $* * * *$ \\
\hline SPC24 & Kinetochore protein Spc24 & 2.20 & -0.53 & $* * * *$ \\
\hline MYBL2 & Myb-related protein B & 2.33 & -0.52 & $* * * *$ \\
\hline KIF18B & Kinesin-like protein KIF18B & 1.66 & -0.51 & $* * * *$ \\
\hline FAM111B & Protein FAM111B & 0.68 & -0.51 & $* * * *$ \\
\hline TPX2 & Targeting protein for Xklp2 & 7.41 & -0.50 & $* * * *$ \\
\hline IQGAP3 & Ras GTPase-activating-like protein IQGAP3 & 1.59 & -0.50 & $* * * *$ \\
\hline PKMYT1 & $\begin{array}{l}\text { Membrane-associated tyrosine- and threonine-specific } \\
\text { cdc2-inhibitory kinase }\end{array}$ & 1.88 & -0.50 & $* * * *$ \\
\hline
\end{tabular}

${ }^{\ddagger}$ RPKM (Reads Per Kilobase Million) of control MCs. ${ }^{* * * *} p \leq 0.0001$. 


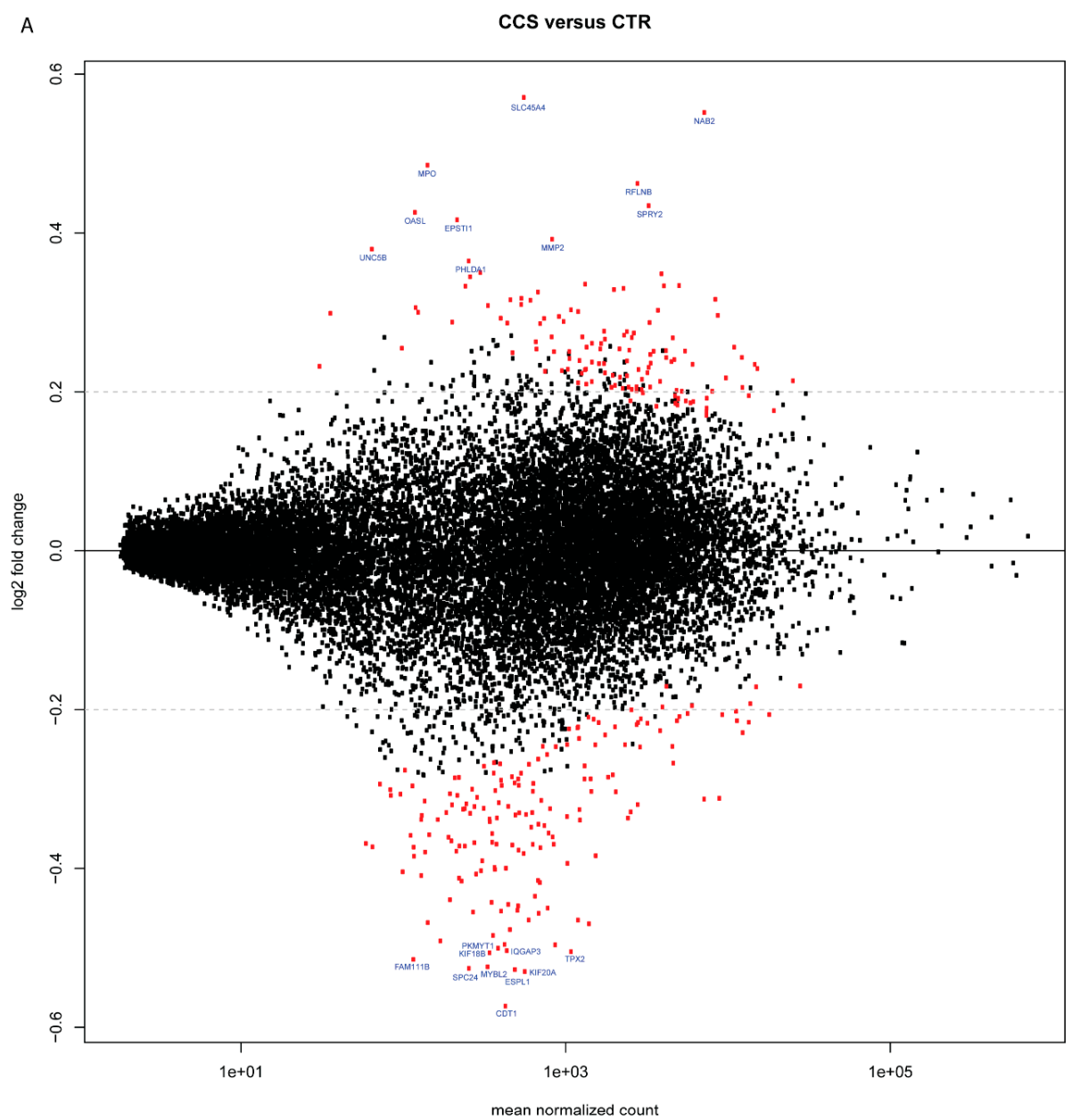

B

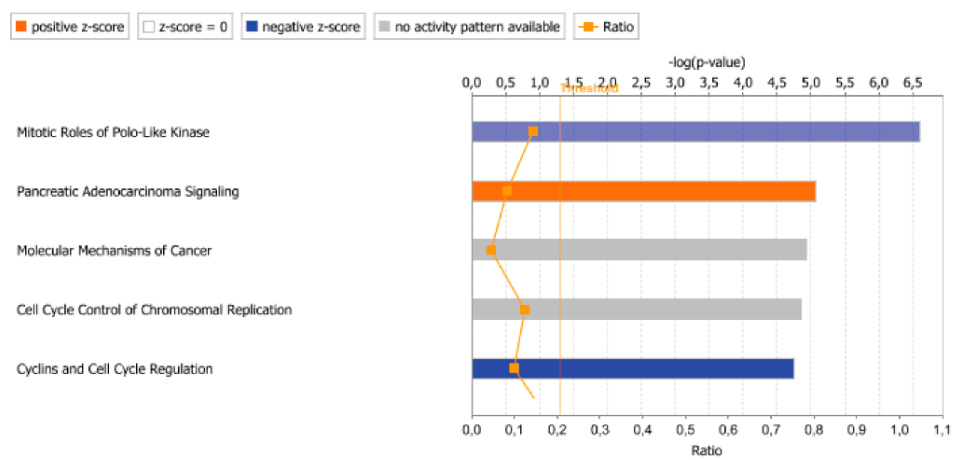

Figure 1. Deregulated genes in MCs cocultured with HT29 spheroids. (A) Plots of normalized mean count (gene expression) versus $\log _{2}$-transformed gene expression fold change $\left(\log _{2} \mathrm{FC}\right)$ for $\mathrm{MCs}$ cocultured with HT29 spheroids (CCS) versus MCs alone (CTR). Each dot represents a transcript. Dots in red were significantly differentially up- or downregulated $(p<0.05)(n=2)$. Dots labeled with the gene symbol were the top 10 upregulated or downregulated genes. The $p$ values were computed by the Wald test and corrected by the Benjamini-Hochberg procedure. The black horizontal line denotes the base line level and the grey horizontal line denotes the value of $\log _{2} F C=0.2$. (B) The top 5 canonical pathways enriched in CCS. Pathways in red indicate activated and those in blue, suppressed. Pathways in grey indicate no functional prediction available. The vertical line denotes the significance level of $\alpha$ $=0.05$. (- $\square-)$ The ratio represents the number of genes from the dataset that are part of the pathway. 
On the other hand, pathways related to cell division, such as "mitotic roles of polo-like kinase" and "cyclins and cell cycle regulation" were suppressed (Figure 1B). Indeed, among the top 10 downregulated genes, KIF20A and KIF18B are linked to cell proliferation [27]. SPC24 and CDT1 regulate DNA replication [28] and ESPL1, MYBL2, TPX2 are related to cell mitosis/cell cycle control $[29,30]$.

\subsection{Gene Deregulation for Extracellular Mediators in Colon Cancer-Cocultured MCs}

To more precisely understand how colon cancer cells may shape MCs to become pro-tumorigenic, we further sorted those 281 deregulated genes based on the following criteria: (1) MC markers; (2) involvement in colon cancer pathology or (3) involvement in tumor-stromal interaction. Genes for extracellular mediators were evaluated to estimate the action of MCs on colon cancer cells. Classical MC mediators, such as PDGF-A, VEGF-A, and MMP-2 were significantly upregulated in CCS (Table 2), suggesting that colon cancer cells potentially augment MC-mediated tumor growth, angiogenesis and invasion. Because non-protein mediators (e.g., amines, lipids) cannot be directly analyzed by RNA sequencing, key enzymes for their synthesis were evaluated. Intriguingly, PTGS2 (also known as COX2) was upregulated in CCS (Table 2). In addition to classic MC mediators, transcripts of TNFSF14 (also called LIGHT) and ISG15 (IFN-stimulated gene 15) were also upregulated in CCS (Table 2). LIGHT can be secreted by human MCs [31] and plays a role in colon cancer pathology [32,33]. ISG15 has been shown to enhance the tumorigenic potential of cancer stem cells [34]. Since ISG15 is also an interferon-stimulated gene, its upregulation may indicate the presence of interferon signals in the coculture. Indeed, another interferon inducible gene, i.e., EPSTI1, was also upregulated in CCS (Table 1).

Table 2. Genes of interest in CCS versus CTR.

\begin{tabular}{|c|c|c|c|c|c|}
\hline Gene Symbol & Name & Cytolocation & Gene Expression * & $\log _{2} \mathrm{FC}$ & Adjusted $p$ Value \\
\hline MMP2 & Matrix metalloproteinase-2 & Extracellular & 3.23 & 0.39 & $* * * *$ \\
\hline VEGFA & Vascular endothelial growth factor A & Extracellular & 2.51 & 0.23 & * \\
\hline PDGFA & Platelet-derived growth factor subunit A & Extracellular & 3.84 & 0.29 & ** \\
\hline ISG15 & Interferon-stimulated gene 15 & Extracellular & 25.01 & 0.34 & $* *$ \\
\hline NPTX1 & Neuronal pentraxin-1 & Extracellular & 1.66 & -0.38 & $* * *$ \\
\hline PTGS2 & Prostaglandin G/H synthase 2 & Cytoplasm & 1.42 & 0.35 & $* *$ \\
\hline RHOB & Rho-related GTP-binding protein RhoB & Cytoplasm & 35.05 & -0.22 & * \\
\hline STAT1 & $\begin{array}{c}\text { Signal transducer and activator of transcription } \\
1 \text {-alpha/beta }\end{array}$ & Nucleus & 14.78 & 0.27 & $* *$ \\
\hline NOTCH1 & Neurogenic locus notch homolog protein 1 & Membrane & 10.18 & 0.35 & $* * * *$ \\
\hline PTGER4 & Prostaglandin E2 receptor EP4 subtype & Membrane & 1.16 & 0.29 & * \\
\hline FZD1 & Frizzled-1 & Membrane & 3.09 & 0.32 & * \\
\hline UNC5B & Netrin receptor UNC5B & Membrane & 0.20 & 0.38 & $* * *$ \\
\hline IL18RAP & Interleukin-18 receptor accessory protein & Membrane & 0.56 & 0.25 & $*$ \\
\hline TJP2 & Tight junction protein ZO-2 & Membrane & 11.75 & -0.22 & * \\
\hline
\end{tabular}

\subsection{Gene Deregulation for Membrane Receptors in Colon Cancer-Cocultured MCs}

By examining the transcript for plasma membrane receptors in CCS, we may speculate the increased ligand-receptor interaction in the cellular crosstalk between MCs and HT29 cells. Human MCs constitutively express multiple PGE2 receptors (EP2, EP3 and EP4) [35]. Coculture with HT29 cells induced increased EP4 in MCs (Table 2), indicating a possible enhanced PGE2-EP4 interaction in the cellular crosstalk. Of note, NOTCH1 and its downstream molecule RELA (a nuclear factor NF- $\mathrm{kB}$ subunit) were upregulated in CCS (Table 2). In supporting this, HT29 cells secret high amounts of notch1 ligands (e.g., JAG2) [36]. Other receptors such as FZD1 (frizzled 1) and UNC5B (netrin receptor) were also upregulated in CCS (Table 2). Indeed, Wnt (ligand for frizzled-1) and Netrin can be secreted by colon cancer cells $[37,38]$. Upon stress, colon epithelial cells can release multiple alarmins, such as 
IL-18, IL-33 and ATP [39]. Based on this, we also observed upregulation of IL18RAP (an IL-1 receptor family) and P2RY11 (a purinergic receptor) in CCS (Table 2).

On the other hand, transcriptome analysis of membrane receptors may provide a better insight into how colon cancer cells may modify MC activity. For instance, ITGA3 (gene coding for $\alpha_{3} \beta_{1}$ integrin), ITGA2 (gene coding for $\alpha_{2} \beta_{1}$ integrin) as well as their downstream molecules, i.e., RHOB and CIT were found downregulated in CCS (Table 2). It has been shown that $\alpha_{3} \beta_{1}$ integrin mediates MC adhesion and migration on basal membrane laminins [40] and $\alpha_{2} \beta_{1}$ integrin is necessary for MC-induced acute inflammatory responses against bacteria [41]. These data, together with downregulated HMMR (hyaluronan mediated motility receptor) and TJP2 (tight junction protein zo-2) (Table 2), suggest a reduced cytokinesis, cytoskeleton organization and cell trafficking ability of CCS (Figure 1B).

\subsection{Deregulated Genes in TLR2-Primed MCs Cocultured with Colon Cancer Cells}

We hypothesized that colon cancer cells may provide a first signal to stimulate MCs in the early phase, and as cancer grows, danger signals derived from stressed cancer cells or exogenous pathogens in the gut may give a second wave of stimuli. In our previous study, we showed that TLR2 pre-stimulation (FSL-1) of MCs can induce a stronger growth of HT29 spheroids [23]. To anticipate how the combination of HT29 and TLR2 stimuli may influence MC activity, we compared the transcriptome signature of MCs that received TLR2 stimulation prior to the coculture with HT29 spheroids (TLR2-CCS) versus control MCs (CTR). At the specified significance level of corrected $p$ value $<0.05$ and $\log _{2} \mathrm{FC}>0.2,197$ genes were deregulated in TLR2-CCS (Figure 2A and Table 3). Pathway analysis showed the enhancement of "interferon signaling", "antigen presenting pathway" and T helper cell pathways (Figure 2B). Among those 197 candidates, we further sorted the interesting candidates based on the previous selection criteria.

Table 3. The top-10 deregulated genes in TLR2-CCS versus CTR.

\begin{tabular}{|c|c|c|c|c|}
\hline Gene Symbol & Name & Gene Expression $\ddagger$ & $\log _{2} \mathrm{FC}$ & Adjusted $p$ Value \\
\hline \multicolumn{5}{|l|}{ upregulated } \\
\hline IFI44 & Interferon-induced protein 44 & 0.90 & 0.86 & $* * * *$ \\
\hline ISG15 & Interferon-stimulated gene 15 & 25.01 & 0.84 & $* * * *$ \\
\hline IFIT1 & Interferon-induced protein with tetratricopeptide repeats 1 & 2.05 & 0.79 & $* * * *$ \\
\hline IFI6 & Interferon alpha-inducible protein 6 & 14.49 & 0.68 & $* * * *$ \\
\hline HERC6 & Probable E3 ubiquitin-protein ligase HERC6 & 1.24 & 0.53 & $* * * *$ \\
\hline IRF7 & Interferon regulatory factor 7 & 13.80 & 0.49 & $* * * *$ \\
\hline H1F0 & Histone $\mathrm{H} 1.0$ & 21.75 & 0.47 & $* * * *$ \\
\hline MX2 & Interferon-induced GTP-binding protein $\mathrm{Mx2}$ & 0.79 & 0.47 & $* * * *$ \\
\hline ARRDC3 & Arrestin domain-containing protein 3 & 3.42 & 0.46 & $* * * *$ \\
\hline OAS3 & $2^{\prime}-5^{\prime}$-oligoadenylate synthase 3 & 0.07 & 0.45 & $* * * *$ \\
\hline \multicolumn{5}{|l|}{ downregulated } \\
\hline IL18R1 & Interleukin-18 receptor 1 & 26.24 & -0.44 & $* * * *$ \\
\hline ZNF850 & Zinc finger protein 850 & 1.10 & -0.37 & $* *$ \\
\hline PDE5A & cGMP-specific $3^{\prime}, 5^{\prime}$-cyclic phosphodiesterase & 0.98 & -0.36 & $* *$ \\
\hline SCAI & Protein SCAI & 1.75 & -0.35 & $* * *$ \\
\hline ENSG00000140181 & N/A & 5.13 & -0.34 & $* * *$ \\
\hline APAF1 & Apoptotic protease-activating factor 1 & 4.32 & -0.33 & $* *$ \\
\hline JUN & Transcription factor AP-1 & 16.81 & -0.33 & $* *$ \\
\hline RYR3 & Ryanodine receptor 3 & 5.47 & -0.33 & $* * * *$ \\
\hline PPP1R10 & Serine/threonine-protein phosphatase 1 regulatory subunit 10 & 17.85 & -0.31 & $* * * *$ \\
\hline TXLNB & Beta-taxilin & 2.86 & -0.31 & $*$ \\
\hline
\end{tabular}

${ }^{\ddagger}$ RPKM (Reads Per Kilobase Million) of control MCs. ${ }^{*} p \leq 0.05 ;{ }^{* *} p \leq 0.01 ; p \leq 0.001 ;{ }^{* * *} p \leq 0.0001$. 
A

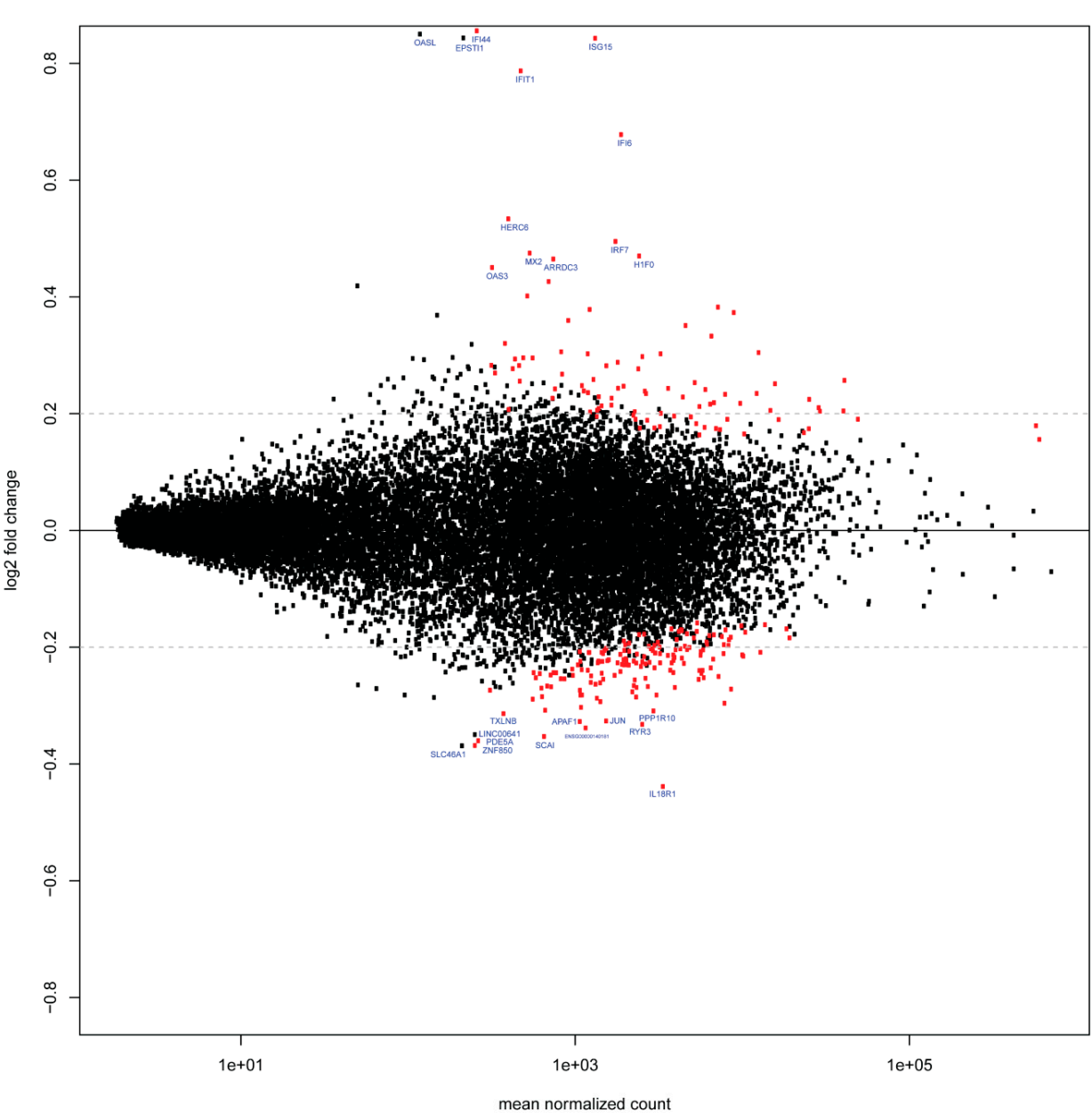

B

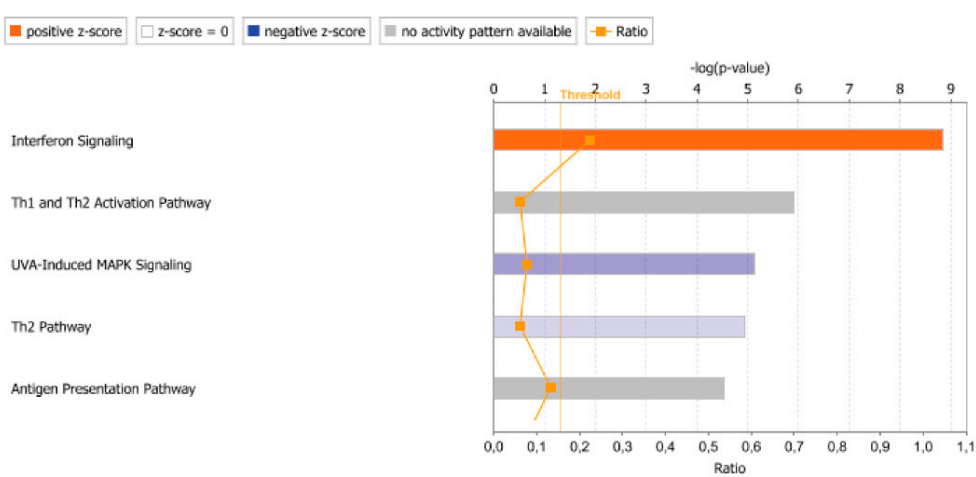

Figure 2. Deregulated genes in TLR2-primed MCs cocultured with HT29 spheroids. (A) Plots of normalized mean count (gene expression) versus $\log _{2}$-transformed gene expression fold change $\left(\log _{2}\right.$ FC) for TLR2-primed MCs cocultured with HT29 spheroids (TLR2-CCS) versus control MCs (CTR). Each dot represents a transcript. Dots in red were significantly differentially up- or downregulated $(p<0.05)(n=2)$. Dots labeled with the gene symbol were the top 10 upregulated or downregulated genes. The $p$ values were computed by the Wald test and were corrected by the Benjamini-Hochberg procedure. The black horizontal line denotes the base line level and the grey horizontal line denotes the value of $\log _{2} \mathrm{FC}=0.2$. (B) The top 5 canonical pathways enriched in TLR2-CCS. Pathways in red indicate activated and in blue suppressed. Pathways in grey indicate no functional prediction available. The vertical line denotes the significance level of $\alpha=0.05$. (- $\square-)$ The ratio represents the number of genes from the dataset that are part of this pathway. 


\subsection{Gene Deregulation for Extracellular Mediators in TLR2-Primed MCS Cocultured with Colon Cancer Cells}

Similar to CCS, increased MMP2, ISG15 and TNFSF14 were also found in TLR2-CCS (Table 4), suggesting that the upregulation might, most likely, be induced by HT29 cells instead of TLR2 stimulation. Of note, ISG15 was the most significant deregulated gene in TLR2-CCS with $\log _{2} \mathrm{FC}=0.84$ (Figure 2A and Table 3). This effect was not due to the direct consequence of TLR2 triggering, as no increase in ISG15 was observed in TLR2-primed MCs alone (data not shown). Moreover, upstream signaling molecules of ISG15, such as STAT1 and IRF7 (Interferon regulatory factor 7), were also found upregulated in TLR2-CCS (Table 4), supporting the enhancement of the "interferon signaling" pathway. In line with this, expression of other interferon inducible genes, i.e., IFI44, IFIT1, IFI6 and MX2, also significantly increased (Figure 2A and Table 3). Interestingly, gene coding for 5-lipoxygenase (ALOX5) was upregulated in TLR2-CCS (Table 4). Since 5-lipoxygenase is a key enzyme responsible for synthesizing leukotrienes in MCs, upregulation of ALOX5 may suggest an increased production of leukotrienes in TLR2-CCS. On the other hand, gene NDST2 (n-deacetylase/ $n$-sulfotransferase-2) was downregulated in TLR2-CCS (Table 4) and NDST2 is a crucial enzyme for heparin biosynthesis in MCs. Different from CCS, there was no significant deregulation of VEGFA, PDGFA and COX2 in TLR2-CCS (data not shown).

Table 4. Genes of interest in TLR2-CCS versus CTR.

\begin{tabular}{|c|c|c|c|c|c|}
\hline Gene Symbol & Name & Cytolocation & Gene Expression* & $\log _{2} \mathrm{FC}$ & Adjusted $p$ Value \\
\hline ISG15 & Interferon-stimulated gene 15 & Extracellular & 25.01 & 0.84 & $* * * *$ \\
\hline MMP2 & Matrix metalloproteinase-2 & Extracellular & 3.23 & 0.31 & ** \\
\hline TNFSF14 & Tumor necrosis factor ligand superfamily member 14 & Extracellular & 2.04 & 0.27 & * \\
\hline ALOX5 & Arachidonate 5-lipoxygenase & Nucleus & 35.70 & 0.21 & * \\
\hline IRF7 & Interferon regulatory factor 7 & Nucleus & 13.79 & 0.49 & $* * * *$ \\
\hline STAT1 & Signal transducer and activator of transcription 1-alpha/beta & Nucleus & 14.78 & 0.35 & $* * * *$ \\
\hline HLA-DPA1 & HLA class II histocompatibility antigen, DP alpha 1 chain & Membrane & 6.69 & 0.21 & * \\
\hline HLA-DRA & HLA class II histocompatibility antigen, DR alpha chain & Membrane & 4.57 & 0.28 & * \\
\hline CD74 & HLA class II histocompatibility antigen gamma chain & Membrane & 17.18 & 0.30 & $* * *$ \\
\hline ITGB7 & Integrin beta- 7 & Membrane & 7.11 & 0.23 & * \\
\hline
\end{tabular}

\subsection{Gene Deregulation for Membrane Receptors in TLR2-Primed MCs Cocultured with Colon Cancer Cells}

Next, to determine to what extent the deregulated genes in TLR2-CCS are involved in antigen presenting signaling, we sorted genes that are enriched in this pathway. Intriguingly, MHC class molecules, such as HLA-B (MHC I, B), HLA-C (MHC I, C), HLA-DPA1 (MHC II DP a), HLA-DRA (MHC II DR a) and CD74 (MHC II $\gamma$ chain), were significantly upregulated in TLR2-CCS (Table 4). Because this was not observed in TLR2-primed MCs alone (data not shown), we do not expect that TLR2 stimulation triggers the upregulation. In addition, ITGB7 (coding for $B 7$ integrin) was upregulated in TLR2-CCS (Table 4). B7 integrin is an important molecule for MC homing to the small intestine in mice [42]. Nevertheless, there are no data available to predict its biological meaning in human MCs [43]. In contrast to CCS, no upregulation of ITGA2/3, EP4, NOTCH1, FZD1 or UNC5B was observed in TLR2-CCS (data not shown).

\section{Discussion}

Although a significant role for MCs in colon cancer is well recognized in mouse and human studies, the underlying mechanism is poorly defined. Here, we analyzed the effect of MC-colon cancer interplay on MC transcriptome profile. We identified a list of deregulated genes in MC when cocultured with HT29 colon cancer. Pathway enrichment analysis revealed these genes are involved in cancer-associated signaling. This study may initiate an understanding how colon cancer cells can shape the phenotype and function of MCs and vice versa, how MCs may contribute to colon cancer development. 
We show that HT29 colon cancer cells induced an increased expression of VEGF-A, PDGF-A and MMP2 in MCs. This supports the notion that colon cancer can educate MCs to be a pro-tumorigenic player. It has been reported that IL-8 induces MMP2 production in endothelial and neuron cells [44,45]. Based on our previous finding, increased IL-8 levels were detected in the coculture [23]. We speculate that the upregulation of MMP2 in CCS might be, at least partly, caused by IL-8 derived from HT29. The upregulation of COX2 may indicate an increased activity of prostaglandin synthesis in CCS. Still, the production of prostaglandins is also dependent on the availability of substrate - arachidonic acid (AA), which is released from membrane lipids by phospholipase A2 (PLA2). In addition, prostaglandins play different roles in tumorigenesis. For instance, PGD2 has been shown to inhibit colitis-associated colon cancer [46], whereas PGE2 promotes tumor cell growth [47] and immunosuppression in the tumor microenvironment [48]. The upregulation of EP4 in CCS might support an increased interaction of EP4 with PGE2 in the coculture, where the latter can be secreted by colon cancer cells and/or MCs themselves. On the other hand, PGE2 can bind to EP2 on MCs, resulting in enhanced production of VEGF-A $[49,50]$. This speculation is in line with our observation that VEGF-A was upregulated in CCS as well as the coculture supernatant [23]. Pathway enrichment analysis showed the enhancement of "pancreatic adenocarcinoma signaling", where the Notch1-NF-kB-COX2 pathway was activated (Figure 3). The inhibition of mitosis-related pathways may suggest a reduced proliferation of MCs when in contact with HT29. However, since the analysis was based on databases of mainly non-MC cells, experimental investigation is needed to confirm these pathways in human MCs.

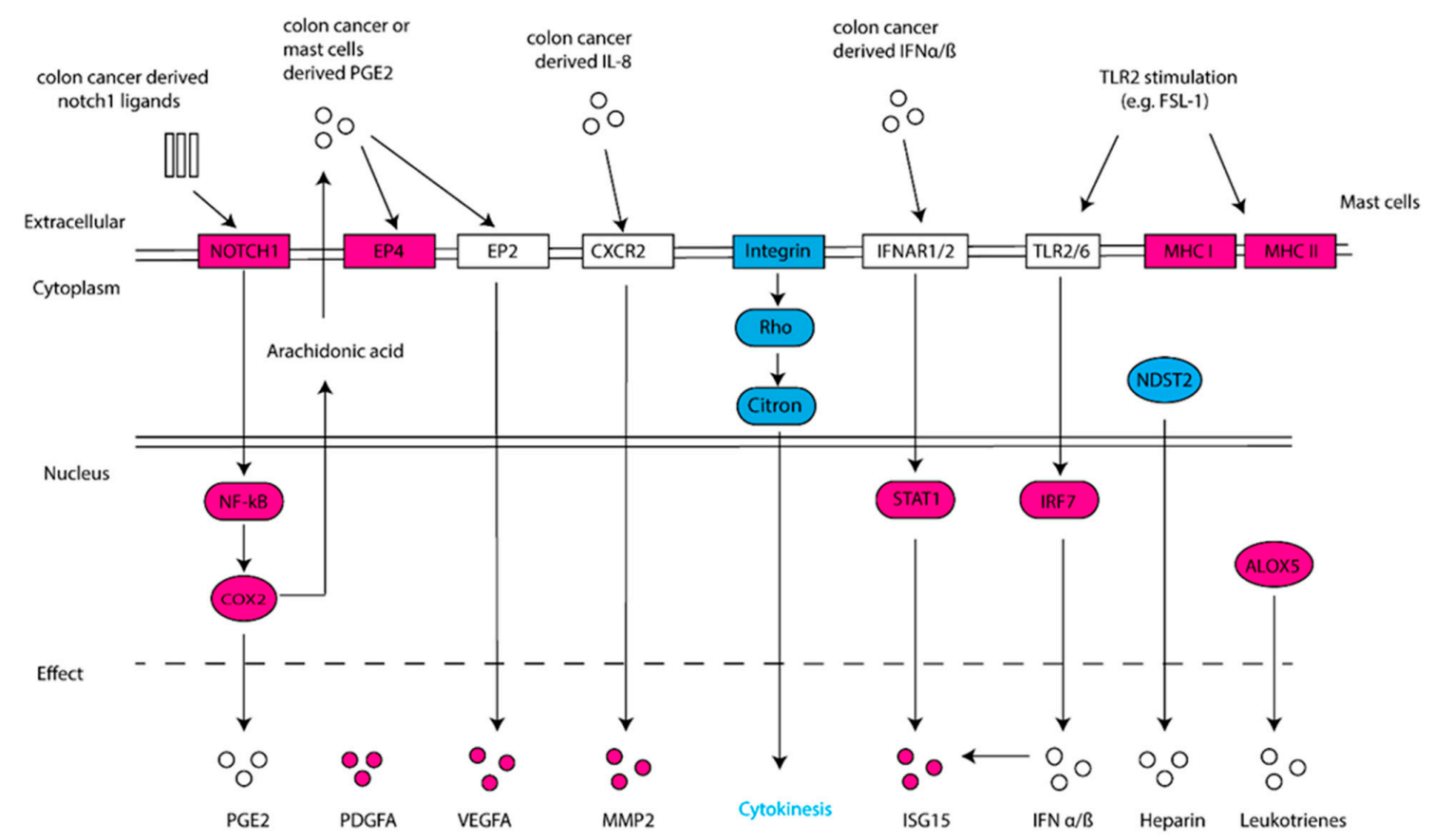

Figure 3. Schematic overview of deregulated genes and associated pathways. Differentially upregulated genes are shown in red and downregulated genes in blue. Pathways and associated upstream/downstream molecules are predicted.

Stressed and dying cancer cells release endogenous "danger" signals, such as ATP, S100 and HMGB1, which bind and activate the pattern recognition receptors (PRRs), frequently TLR2 or TLR4, to trigger immune responses [51]. As such, MCs were pre-stimulated with a TLR2 agonist (FSL-1) prior to the coculture with HT29 colon cancer. In particular, ISG15 was upregulated in CCS and most interestingly, its upregulation was enhanced upon TLR2 stimulation, leading to the most significant $\log _{2}$ FC in TLR2-CCS. It has been shown that ISG15 can promote cancer stem cell growth [34], yet it still remains an open question whether it is a pro- or anti-tumor factor. Some studies suggest the 
effect depends on whether it is in a free or conjugated form [52]. For instance, free ISG15 can exert an antitumor response by activating the innate and adaptive immunity at the tumor site [53]. In addition to ISG15, other interferon inducible genes (e.g., IFI44, IFIT1, IFI6) were also upregulated in TLR2-CCS. Since type I IFNs are potent stimuli for ISG15 production as well as other interferon inducible genes [54], our data may imply that HT29 colon cancer could, through the secretion of IFN $\alpha / \beta$, increase ISG15 production in MCs (Figure 3).

Another interesting finding is the upregulation of MHC class molecules-i.e., MHC I B, MHC I C, HLA-DPA1, HLA-DRA and CD74-in TLR2-CCS. The notion that MCs function as antigen presenting cells is not new, since several studies have shown that IFN- $\gamma$ combined with or without TLR agonists induces MHC II expression on MCs [55-57]. However, IFN- $\gamma$ was not detectable in the coculture supernatant (data not shown), indicating that mediators other than IFN- $\gamma$ are involved. On the other hand, IFN- $\alpha / \beta$ has been shown to stimulate upregulation of MHC class molecules in dendritic cells (DCs) and IFN- $\alpha$ primed DCs proved to be more susceptible for TLR stimulation [58]. This leads to an interesting question whether IFN- $\alpha / \beta$ together with a TLR2 agonist can induce MCs to become antigen-presenting cells. Since the MHC upregulation was not observed in MCs that only received TLR2 stimulation, we speculate that both the stimuli from HT29 coculture and TLR2 agonist are indispensable. Together, these data shed light on the potential of MCs being tailored to increase tumor immunogenicity.

Although most upregulated genes in CCS are associated with pro-tumor properties, the upregulation of TNFSF14 might have an opposite effect. Maker and co-workers have shown that increased expression of TNFSF14 enhances the activity of cytotoxic T-lymphocytes and thereby mediates immune eradication of colon cancer metastases $[33,59]$. Therefore, it is important to recognize the molecular profile of tumor infiltrating MCs, and the contribution of MCs may vary based on the balance of pro- and anti-tumor factors. This might, at least partly, explain why studies have opposite observations regarding the correlation of MC numbers and clinical outcomes in CRC. The limitation of our study is the small sample size $(n=2)$. As a consequence, some genes such as EPSTI1 and OASL display high $\log _{2} \mathrm{FC}$ in TLR2-CCS, but they did not reach statistical significance.

By using a 3D coculture model, our study provides an alternative approach to study the phenotype and activity of (colon) cancer-associated MCs. The transcriptome signature of HT29-cocultured MCs potentially reflects the mechanism of how colon cancer cells may shape MCs to become a pro-tumor player in the early phase and how a subsequent inflammatory signal (e.g., TLR2 ligands) may modify their responses in the cancer milieu. In addition, our data suggest the importance of lipid mediators in MC-colon cancer interaction. Nevertheless, the molecular signature as well as the downstream signaling are based on transcript expression and enrichment analysis. Future studies are needed to further validate the expression and function of targeted proteins and lipids produced by MCs in colon cancer.

\section{Materials and Methods}

Peripheral autologous hematopoietic stem cells derived from patients were used after written informed consent as approved by the ethics committee (TCBio 16-089) of the Utrecht Medical Center, Utrecht, the Netherlands, in accordance with the Declaration of Helsinki (59th WMA General Assembly, Seoul, October 2008), and in compliance with guidelines from the Ethical Committee and European Union legislation.

\subsection{Generation of Primary Human MCs}

CD34+-derived human MCs were generated from surplus autologous stem cell concentrates as previously described by Schmetzer at al. [22]. Briefly, frozen stem cell concentrates were rapidly thawed at $37^{\circ} \mathrm{C}$ under sterile conditions and poured into a large cell culture flask (Greiner Bio-One, Kremsmünster, Austria). Then, 20\% human serum albumin clinical solution (HSA) (Sanquin, Utrecht, the Netherlands), $6 \%$ hydroxyethyl starch clinical solution (Braun, Kronberg im Taunus, Germany) 
and RMPI containing $10 \mathrm{U} / \mathrm{mL}$ Heparin (LEO pharma, Ballerup, Denmark) were added slowly and consecutively to the cell concentrate. Cells were then filtered through a cell dissociation sieve (Sigma-Aldrich, St. Louis, MO, USA) and incubated with 200 U.I./mL DNAse (Roche, Basel, Switzerland) for $15 \mathrm{~min}$. After washing, cells were resuspended in PBS containing 4\% HSA and incubated with Fc-Block (Miltenyi Biotec, Bergisch Gladbach, Germany) for $15 \mathrm{~min}, \mathrm{CD} 34^{+}$positive selection cocktail (STEMCELL Technologies, Vancouver, BC, Canada) for $15 \mathrm{~min}$ and nanoparticles for 10 min. Subsequently, CD $34^{+}$cells were sorted with an EasySep ${ }^{\circledR}$ Magnet (STEMCELL Technologies, Vancouver, BC, Canada) according to the manufacturer's protocol. Finally, sorted cells were resuspended in serum-free expansion medium (SFEM, STEMCELL Technologies) supplemented with human LDL (50 $\mu \mathrm{g} / \mathrm{mL}$, STEMCELL Technologies). On day 1, human recombinant IL-3 (100 ng/mL, Biolegend, San Diego, CA, USA) and SCF (100 ng/mL, Miltenyi Biotec) were added. Every three to four days, IL-3 and SCF were added to a final concentration of $20 \mathrm{ng} / \mathrm{mL}$. At the end of the second week, MCs were maintained under $20 \mathrm{ng} / \mathrm{mL} \mathrm{SCF}$ with the withdrawal of IL-3. From day 17 on, cells were used in described experiments. To obtain high quality, cell viability and purity, cells were further purified using a dead cell removal kit (Miltenyi Biotec) were added. Every three to four days, IL-3 and SCF were added to a final concentration of $20 \mathrm{ng} / \mathrm{mL}$ ) followed by CD117 positive selection (Miltenyi Biotec) according to the manufacturer's protocol. Mature MCs were identified based on the surface expression of CD117 and FceRIa by flow cytometry, as previously described [23].

\subsection{Colon Cancer Cell Lines}

Human colon cancer cells HT29 were obtained from American Type Tissue Culture Collection. HT29 was grown in McCoy medium (Thermo Fisher Scientific, Waltham, MA, USA) supplemented with heat-inactivated 10\% fetal calf serum (FCS, Thermo Fisher Scientific), and $100 \mu \mathrm{g} / \mathrm{mL}$ penicillin and streptomycin (Thermo Fisher Scientific). Cells were cultured in a humidified $37^{\circ} \mathrm{C} / 5 \% \mathrm{CO}_{2}$ incubator.

\subsection{Colon Cancer Spheroids}

Multicellular cancer spheroids were formed using the hanging drop method [60]. Briefly, drops of 250 HT29 cells in $20 \mu \mathrm{L}$ were made in standard medium and incubated upside-down for 4 days. Cancer spheroids were then embedded in extracellular matrix (ECM) as previously described [61]. ECM mixture was prepared on ice containing Matrigel (Corning Inc., Corning, NY, USA) and non-pepsinized rat-tail collagen type $\mathrm{I}(2.3 \mathrm{mg} / \mathrm{mL})$ (Corning $\mathrm{Inc}$.) at a ratio of 1:1 or 1:100. Spheroids suspended in $40 \mu \mathrm{L}$ of pre-heated culture medium were mixed with $200 \mu \mathrm{L}$ of 1:1 ECM (Matrigel: Collagen type I). $50 \mu \mathrm{L}$ drops of spheroid-ECM mixtures were then placed in a 24-well plate previously coated with 1:100 ECM (Matrigel: Collagen type I) base layer. For full polymerization of the gel, plates were incubated at $37^{\circ} \mathrm{C}$ for $1 \mathrm{~h}$. Subsequently, $1 \mathrm{~mL}$ coculture medium with or without human MCs $\left(2 \times 10^{5} / \mathrm{mL}\right)$ was added. Alternately, MCs were pre-stimulated with FSL-1 $(1 \mu \mathrm{g} / \mathrm{mL}$, InvivoGen, San Diego, CA, USA) at $37^{\circ} \mathrm{C}$ for $4 \mathrm{~h}$ and thereafter extensively washed to remove excess FSL-1. After 6-day coculture, MCs were isolated from the coculture to obtain RNA samples (Figure 4).

\subsection{Isolation and Purification of MCs}

Collagenase/dispase ( $1 \mathrm{mg} / \mathrm{mL}$ ) (Sigma-Aldrich) was added to the ECM mixture and incubated at $37^{\circ} \mathrm{C}$ for $1 \mathrm{~h}$. Cells were then washed with PBS supplemented with $1 \%$ BSA and subsequently stained with viability dye YO-PRO1 and antibodies (Thermo Fisher Scientific) for CD117 and FceRIa. Viable cells were gated based on negative expression of YO-PRO1, followed by the sorting based on co-expression of FceRIa and CD117 using BD Influx ${ }^{\mathrm{TM}}$ cell sorter (BD Biosciences, San Jose, CA, USA). Control MCs cultured in ECM without HT29 spheroid were isolated and sorted in an identical way as HT29-cocultured MCs. The purity of isolated MCs was identified by flow cytometry as previously reported [23]. Around $4.5 \times 10^{4}$ and $3 \times 10^{5}$ purified MCs were obtained from donor 1 and 2, respectively, for subsequent RNA isolation. RNA was isolated using PureLink RNA mini kit (Thermo Fisher Scientific), according to the manufacturer's protocol. 


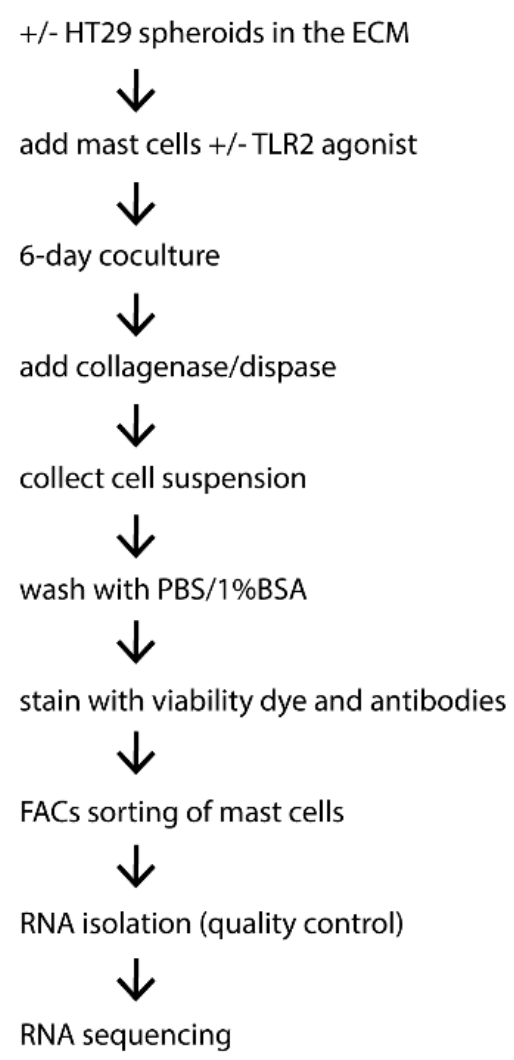

Figure 4. Brief overview of the experimental procedure to obtain mast cell RNA samples from the coculture with colon cancer spheroids.

\subsection{Transcriptome Analysis}

RNA samples of human MCs were sequenced on an Illumina Nextseq500 platform according to the manufacturer's procedure by the Utrecht Sequencing Facility of the Utrecht University (http:/ / www.useq.nl/) (access on 16 May 2018). Sequencing libraries were generated using TruSeq Stranded mRNA poly A kit. Sequence reads were checked for quality by FastQC (v0.11.4) after which reads were aligned to GRCh37 using STAR (v2.4.2a) and read groups were added using Picard (v1.141). All samples passed QC and were subsequently processed using HTSeq-count (v0.6.1) on ENSEMBL gene definitions (GRCh37, release 74).

\subsection{Detecting Differential Gene Expression}

$\mathrm{R}$ statistical software was used to identify deregulated genes. The $p$ values were computed by the Wald test and corrected by the Benjamini-Hochberg procedure. Transcripts with $\log _{2}$-transformed gene expression fold change $\left(\log _{2} \mathrm{FC}\right)>0.2$ and adjusted $p$ value $<0.05$ were deemed differentially expressed. Enriched canonical pathways and MC marker genes were analyzed using IPA ${ }^{\circledR}$ software (QIAGEN, Hilden, Germany) based on the cutoff $\log _{2} \mathrm{FC}>0.2$ and corrected $p$ value $<0.05$.

Author Contributions: Conceptualization, Y.Y. and F.A.R.; Formal analysis, Y.Y. and B.R.B.; Investigation, Y.Y.; Methodology, Y.Y. and B.R.B.; Project administration, F.A.R.; Supervision, J.G. and F.A.R.; Writing-original draft, Y.Y.; Writing-review \& editing, J.G. and F.R.

Funding: This work was supported by the Nutricia Research and China Scholarship Council under Grant (No. 201408440270).

Acknowledgments: We particularly thank Marcus Maurer and Oliver Schmetzer (Department of Dermatology and Allergy, Charité-Universitätsmedizin Berlin, Germany) for technical assistance in setting up the primary human mast cell culture. We thank Ger Arkesteijn (Faculty of Veterinary Medicine, Utrecht University, NL) for providing professional assistance with the FACS sorting. We thank UMC Utrecht Bioinformatics Expertise Core for 
data analysis and data handling. The UMC Utrecht Bioinformatics Expertise Core is subsidized by the University Medical Center Utrecht, Center for Molecular Medicine.

Conflicts of Interest: The authors declare no conflict of interest.

\section{References}

1. Oldford, S.A.; Marshall, J.S. Mast cells as targets for immunotherapy of solid tumors. Mol. Immunol. 2015, 63, 113-124. [CrossRef]

2. Varricchi, G.; Galdiero, M.R.; Loffredo, S.; Marone, G.; Iannone, R.; Granata, F. Are mast cells MASTers in Cancer? Front. Immunol. 2017, 8, 424. [CrossRef] [PubMed]

3. Kalesnikoff, J.; Galli, S.J. New developments in mast cell biology. Nat. Immunol. 2008, 9, 1215-1223. [CrossRef] [PubMed]

4. Ko, E.A.; Sanders, K.M.; Zhou, T. A transcriptomic insight into the impacts of mast cells in lung, breast, and colon cancers. Oncoimmunology 2017, 6, e1360457. [CrossRef]

5. Acikalin, M.F.; Oner, U.; Topcu, I.; Yasar, B.; Kiper, H.; Colak, E. Tumour angiogenesis and mast cell density in the prognostic assessment of colorectal carcinomas. Dig. Liver Dis. 2005, 37, 162-169. [CrossRef]

6. Ammendola, M.; Rosario, S.; Giuseppe, S.; Giuseppe, D.; Severino, M.; Eustachio, R.; Rosa, P.; Ilaria, M.; Marica, C.; Angelo, V.; et al. Correlation between serum tryptase, mast cells positive to tryptase and microvascular density in colo-rectal cancer patients: Possible biological-clinical significance. PLoS ONE 2014, 9, e99512. [CrossRef] [PubMed]

7. Gulubova, M.; Vlaykova, T. Prognostic significance of mast cell number and microvascular density for the survival of patients with primary colorectal cancer. J. Gastroenterol. Hepatol. 2009, 24, 1265-1275. [CrossRef]

8. Malfettone, A.; Silvestris, N.; Saponaro, C.; Ranieri, G.; Russo, A.; Caruso, S.; Popescu, O.; Simone, G.; Paradiso, A.; Mangia, A. High density of tryptase-positive mast cells in human colorectal cancer: A poor prognostic factor related to protease-activated receptor 2 expression. J. Cell. Mol. Med. 2013, 17, 1025-1037. [CrossRef]

9. Suzuki, S.; Ichikawa, Y.; Nakagawa, K.; Kumamoto, T.; Mori, R.; Matsuyama, R.; Takeda, K.; Ota, M.; Tanaka, K.; Tamura, T.; et al. High infiltration of mast cells positive to tryptase predicts worse outcome following resection of colorectal liver metastases. BMC Cancer 2015, 15, 840. [CrossRef] [PubMed]

10. Wang, S.; Linmei, L.; Renren, S.; Xueting, L.; Junyan, Z.; Zehong, Z.; Zhuofang, H.; Ailin, T. Mast cell targeted chimeric toxin can be developed as an adjunctive therapy in colon cancer treatment. Toxins (Basel) 2016, 8, 71. [CrossRef] [PubMed]

11. Tan, S.Y.; Fan, Y.; Luo, H.S.; Shen, Z.X.; Guo, Y.; Zhao, L.J. Prognostic significance of cell infiltrations of immunosurveillance in colorectal cancer. World J. Gastroenterol. 2005, 11, 1210-1214. [CrossRef] [PubMed]

12. Nielsen, H.J.; Hansen, U.; Chrostensen, I.J.; Reimert, C.M.; Brünner, N.; Moesgaard, F. Independent prognostic value of eosinophil and mast cell infiltration in colorectal cancer tissue. J. Pathol. 1999, 189, 487-495. [CrossRef]

13. Visciano, C.; Liotti, F.; Prevete, N.; Cali, G.; Franco, R.; Collina, F.; de Paulis, A.; Marone, G.; Santoro, M.; Melillo, R.M. Mast cells induce epithelial-to-mesenchymal transition and stem cell features in human thyroid cancer cells through an IL-8-Akt-Slug pathway. Oncogene 2015, 34, 5175-5186. [CrossRef] [PubMed]

14. Jiménez-Andrade, G.Y.; Ibarra-Sánchez, A.; González, D.; Lamas, M.; González-Espinosa, C. Immunoglobulin E induces VEGF production in mast cells and potentiates their pro-tumorigenic actions through a Fyn kinase-dependent mechanism. J. Hematol. Oncol. 2013, 6, 56. [CrossRef]

15. Aoki, M.; Pawankar, R.; Niimi, Y.; Kawana, S. Mast cells in basal cell carcinoma express VEGF, IL-8 and RANTES. Int. Arch. Allergy Immunol. 2003, 130, 216-223. [CrossRef]

16. Grützkau, A.; Krüger-Krasagakes, S.; Baumeister, H.; Schwarz, C.; Kögel, H.; Welker, P.; Lippert, U.; Henz, B.M.; Möller, A. Synthesis, storage, and release of vascular endothelial growth factor/vascular permeability factor (VEGF/VPF) by human mast cells: Implications for the biological significance of VEGF206. Mol. Biol. Cell 1998, 9, 875-884. [CrossRef]

17. Coussens, L.M.; Raymond, W.W.; Bergers, G.; Laig-Webster, M.; Behrendtsen, O.; Werb, Z.; Caughey, G.H.; Hanahan, D. Inflammatory mast cells up-regulate angiogenesis during squamous epithelial carcinogenesis. Genes Dev. 1999, 13, 1382-1397. [CrossRef] [PubMed] 
18. Huang, B.; Lei, Z.; Zhang, G.M.; Li, D.; Song, C.; Li, B.; Liu, Y.; Yuan, Y.; Unkeless, J.; Xiong, H.; et al. SCF-mediated mast cell infiltration and activation exacerbate the inflammation and immunosuppression in tumor microenvironment. Blood 2008, 112, 1269-1279. [CrossRef] [PubMed]

19. Zaiss, D.M.; van Loosdregt, J.; Gorlani, A.; Bekker, C.P.; Gröne, A.; Sibilia, M.; van Bergen en Henegouwen, P.M.; Roovers, R.C.; Coffer, P.J.; Sijts, A.J. Amphiregulin enhances regulatory T cell-suppressive function via the epidermal growth factor receptor. Immunity 2013, 38, 275-284. [CrossRef] [PubMed]

20. Shikotra, A.; Ohri, C.M.; Green, R.H.; Waller, D.A.; Bradding, P. Mast cell phenotype, TNF $\alpha$ expression and degranulation status in non-small cell lung cancer. Sci. Rep. 2016, 6, 38352. [CrossRef]

21. Young, M.D.; Wakefield, M.J.; Smyth, G.K.; Oshlack, A. Gene ontology analysis for RNA-seq: Accounting for selection bias. Genome Biol. 2010, 11, R14. [CrossRef] [PubMed]

22. Schmetzer, O.; Valentin, P.; Smorodchenko, A.; Domenis, R.; Gri, G.; Siebenhaar, F.; Metz, M.; Maurer, M. A novel method to generate and culture human mast cells: Peripheral CD34+ stem cell-derived mast cells (PSCMCs). J. Immunol. Methods 2014, 413, 62-68. [CrossRef]

23. Yu, Y.; Blokhuis, B.; Derks, Y.; Kumari, S.; Garssen, J.; Redegeld, F. Human mast cells promote colon cancer growth via bidirectional crosstalk: Studies in 2D and 3D coculture models. OncoImmunology 2018, 7, e1504729. [CrossRef] [PubMed]

24. Said, A.H.; Raufman, J.P.; Xie, G. The role of matrix metalloproteinases in colorectal cancer. Cancers (Basel) 2014, 6, 366-375. [CrossRef] [PubMed]

25. Rymaszewski, A.L.; Tate, E.; Yimbesalu, J.P.; Gelman, A.E.; Jarzembowski, J.A.; Zhang, H.; Pritchard, K.A.; Vikis, $\mathrm{H}$. The role of neutrophil myeloperoxidase in models of lung tumor development. Cancers (Basel) 2014, 6, 1111-1127. [CrossRef] [PubMed]

26. de Neergaard, M.; Kim, J.; Villadsen, R.; Fridriksdottir, A.J.; Rank, F.; Timmermans-Wielenga, V.; Langerød, A.; Børresen-Dale, A.L.; Petersen, O.W.; Rønnov-Jessen, L. Epithelial-stromal interaction 1 (EPSTI1) substitutes for peritumoral fibroblasts in the tumor microenvironment. Am. J. Pathol. 2010, 176, 1229-1240. [CrossRef] [PubMed]

27. Ho, J.R.; Elodie, C.; Lisa, K.; Remy, N.; Simone, B.; Thierry, L.; Yves, A.; Jennifer, S.; François, R.; Bruno, G. Deregulation of rab and rab effector genes in bladder cancer. PLoS ONE 2012, 7, e39469. [CrossRef] [PubMed]

28. Ma, L.; McQueen, J.; Cuschieri, L.; Vogel, J.; Measday, V. Spc24 and Stu2 promote spindle integrity when DNA replication is stalled. Mol. Biol. Cell 2007, 18, 2805-2816. [CrossRef]

29. Musa, J.; Aynaud, M.-M.; Mirabeau, O.; Delattre, O.; Grünewald, T.G.P. MYBL2 (B-Myb): A central regulator of cell proliferation, cell survival and differentiation involved in tumorigenesis. Cell Death Dis. 2017, 8, e2895. [CrossRef] [PubMed]

30. Fu, J.; Bian, M.; Xin, G.; Deng, Z.; Luo, J.; Guo, X.; Chen, H.; Wang, Y.; Jiang, Q.; Zhang, C. TPX2 phosphorylation maintains metaphase spindle length by regulating microtubule flux. J. Cell Biol. 2015, 210, 373-383. [CrossRef]

31. Sibilano, R.; Gaudenzio, N.; DeGorter, M.K.; Reber, L.L.; Hernandez, J.D.; Starkl, P.M.; Zurek, O.W.; Tsai, M.; Zahner, S.; Montgomery, S.B.; et al. A TNFRSF14-FcERI-mast cell pathway contributes to development of multiple features of asthma pathology in mice. Nat. Commun. 2016, 7, 13696. [CrossRef] [PubMed]

32. Qin, J.Z.; Upadhyay, V.; Prabhakar, B.; Maker, A.V. Shedding LIGHT (TNFSF14) on the tumor microenvironment of colorectal cancer liver metastases. J. Transl. Med. 2013, 11, 70. [CrossRef] [PubMed]

33. Maker, A.V. Precise identification of immunotherapeutic targets for solid malignancies using clues within the tumor microenvironment-Evidence to turn on the LIGHT. OncoImmunology 2015, 5, e1069937. [CrossRef]

34. Sainz, B., Jr.; Martín, B.; Tatari, M.; Heeschen, C.; Guerra, S. ISG15 is a critical microenvironmental factor for pancreatic cancer stem cells. Cancer Res. 2014, 74, 7309-7320. [CrossRef] [PubMed]

35. Feng, C.; Beller, E.M.; Bagga, S.; Boyce, J.A. Human mast cells express multiple EP receptors for prostaglandin E2 that differentially modulate activation responses. Blood 2006, 107, 3243-3250. [CrossRef] [PubMed]

36. He, W.; Chan, C.M.; Wong, S.C.; Au, T.C.; Ho, W.S.; Chan, A.K.; Chan, A.S.; Ma, B.B.; Chan, A.T. Jagged 2 silencing inhibits motility and invasiveness of colorectal cancer cell lines. Oncol. Lett. 2016, 12, 5193-5198. [CrossRef] [PubMed]

37. Holcombe, R.F.; Marsh, J.L.; Waterman, M.L.; Lin, F.; Milovanovic, T.; Truong, T. Expression of Wnt ligands and Frizzled receptors in colonic mucosa and in colon carcinoma. Mol. Pathol. 2002, 55, 220-226. [CrossRef]

38. Mehlen, P.; Llambi, F. Role of netrin-1 and netrin-1 dependence receptors in colorectal cancers. Br. J. Cancer 2005, 93, 1-6. [CrossRef] 
39. Nowarski, R.; Jackson, R.; Gagliani, N.; de Zoete, M.R.; Palm, N.W.; Bailis, W.; Low, J.S.; Harman, C.C.; Graham, M.; Elinav, E.; et al. Epithelial IL-18 equilibrium controls barrier function in colitis. Cell 2015, 163, 1444-1456. [CrossRef]

40. Sime, W.; Lunderius-Andersson, C.; Enoksson, M.; Rousselle, P.; Tryggvason, K.; Nilsson, G.; Harvima, I.; Patarroyo, M. Human mast cells adhere to and migrate on epithelial and vascular basement membrane laminins LM-332 and LM-511 via alpha3beta1 integrin. J. Immunol. 2009, 183, 4657-4665. [CrossRef]

41. Edelson, B.T.; Li, Z.; Pappan, L.K.; Zutter, M.M. Mast cell-mediated inflammatory responses require the $\alpha 2 \beta 1$ integrin. Blood 2004, 103, 2214-2220. [CrossRef] [PubMed]

42. Gurish, M.F.; Austen, K.F. Developmental origin and functional specialization of mast cell subsets. Immunity 2012, 37, 25-33. [CrossRef] [PubMed]

43. Dahlin, J.S.; Malinovschi, A.; Öhrvik, H.; Sandelin, M.; Janson, C.; Alving, K.; Hallgren, J. Lin-CD34hi CD117int/hi FceRI+ cells in human blood constitute a rare population of mast cell progenitors. Blood 2016, 127, 383-391. [CrossRef] [PubMed]

44. Li, A.; Dubey, S.; Varney, M.L.; Dave, B.J.; Singh, R.K. IL-8 directly enhanced endothelial cell survival, proliferation, and matrix metalloproteinases production and regulated angiogenesis. J. Immunol. 2003, 170, 3369-3376. [CrossRef] [PubMed]

45. Thirumangalakudi, L.; Yin, L.; Rao, H.V.; Grammas, P. IL-8 induces expression of matrix metalloproteinases, cell cycle and pro-apoptotic proteins, and cell death in cultured neurons. J. Alzheimers Dis. 2007, 11, 305-311. [CrossRef] [PubMed]

46. Iwanaga, K.; Nakamura, T.; Maeda, S.; Aritake, K.; Hori, M.; Urade, Y.; Ozaki, H.; Murata, T. Mast cell-derived prostaglandin D2 inhibits colitis and colitis-associated colon cancer in mice. Cancer Res. 2014, 74, 3011-3019. [CrossRef] [PubMed]

47. Hawcroft, G.; Ko, C.W.; Hull, M.A. Prostaglandin E2-EP4 receptor signalling promotes tumorigenic behaviour of HT-29 human colorectal cancer cells. Oncogene 2007, 26, 3006-3019. [CrossRef] [PubMed]

48. Wang, D.; DuBois, R.N. Inflammatory mediator prostaglandin E2 in colorectal cancer. Cancer J. 2013, 19, 502-510. [CrossRef] [PubMed]

49. Abdel-Majid, R.M.; Marshall, J.S. Prostaglandin E2 induces degranulation-independent production of vascular endothelial growth factor by human mast cells. J. Immunol. 2004, 172, 1227-1236. [CrossRef] [PubMed]

50. Detoraki, A.; Staiano, R.I.; Granata, F.; Giannattasio, G.; Prevete, N.; de Paulis, A.; Ribatti, D.; Genovese, A.; Triggiani, M.; Marone, G. Vascular endothelial growth factors synthesized by human lung mast cells exert angiogenic effects. J. Allergy Clin. Immunol. 2009, 123, 1142. [CrossRef] [PubMed]

51. Schaefer, L. Complexity of danger: The diverse nature of damage-associated molecular patterns. J. Biol. Chem. 2014, 289, 35237-35245. [CrossRef] [PubMed]

52. Han, H.G.; Moon, H.W.; Jeon, Y.J. ISG15 in cancer: Beyond ubiquitin-like protein. Cancer Lett. 2018, 438, 52-62. [CrossRef] [PubMed]

53. Desai, S.D. ISG15: A double edged sword in cancer. Oncoimmunology 2015, 4, e1052935. [CrossRef] [PubMed]

54. Reich, N.; Evans, B.; Levy, D.; Fahey, D.; Knight, E., Jr.; Darnell, J.E., Jr. Interferon-induced transcription of a gene encoding a 15-kDa protein depends on an upstream enhancer element. Proc. Natl. Acad. Sci. USA 1987, 84, 6394-6398. [CrossRef]

55. Lotfi-Emran, S.; Ward, B.R.; Le, Q.T.; Pozez, A.L.; Manjili, M.H.; Woodfolk, J.A.; Schwartz, L.B. Human mast cells present antigen to autologous CD4 + T cells. J. Allergy Clin. Immunol. 2018, 141, 311-321.e10. [CrossRef] [PubMed]

56. Kambayashi, T.; Allenspach, E.J.; Chang, J.T.; Zou, T.; Shoag, J.E.; Reiner, S.L.; Caton, A.J.; Koretzky, G.A. Inducible MHC class II expression by mast cells supports effector and regulatory T cell activation. J. Immunol. 2009, 182, 4686-4695. [CrossRef] [PubMed]

57. Galli, S.J.; Gaudenzio, N. Human mast cells as antigen-presenting cells: When is this role important in vivo? J. Allergy Clin. Immunol. 2018, 141, 92-93. [CrossRef]

58. Gessani, S.; Conti, L.; Del Cornò, M.; Belardelli, F. Type I interferons as regulators of human antigen presenting cell functions. Toxins 2014, 6, 1696-1723. [CrossRef] [PubMed]

59. Qiao, G.; Qin, J.; Kunda, N.; Calata, J.F.; Mahmud, D.L.; Gann, P.; Fu, Y.X.; Rosenberg, S.A.; Prabhakar, B.S.; Maker, A.V. LIGHT elevation enhances immune eradication of colon cancer metastases. Cancer Res. 2017, 77, 1880-1891. [CrossRef] 
60. Timmins, N.E.; Nielsen, L.K. Generation of multicellular tumor spheroids by the hanging-drop method. Methods Mol. Med. 2007, 140, 141-151. [PubMed]

61. Berens, E.B.; Holy, J.M.; Riegel, A.T.; Wellstein, A. A cancer cell spheroid assay to assess invasion in a 3D Setting. J. Vis. Exp. 2015, e53409. [CrossRef] [PubMed] 